\title{
Questionnaire survey of interpreter use in accident and emergency departments in the UK
}

\author{
P Leman, D J Williams
}

\begin{abstract}
Objective-To determine the support for a national telephone interpreter service from accident and emergency (A\&E) departments across the $U K$, and the factors that may influence that support. To determine the nature of interpreter needs for these departments.

Methods-Postal questionnaire survey of 255 A\&E departments in the UK.

Results-A total of 197 replies were received, a response rate of $77.3 \%$. Altogether 186 respondents answered the question on support for a national telephone interpreter service and 124 (66.7\%) would support one. Those departments in favour were no more likely to have required an interpreter in the last seven days $\left(\chi^{2}=0.16, \mathrm{df}=1, \mathrm{p}=0.69\right)$, be in the inner city (Fisher's exact test, two sided probability, $p=1$ ), have predominantly local population needs compared with tourist needs $\left(\chi^{2}=0.65, \mathrm{df}=1, \mathrm{p}=0.42\right)$, or be current users of a telephone interpreter service $\left(\chi^{2}=0.01, d f=1, p=0.93\right)$. Seventy nine of $180(42.9 \%)$ departments had used some form of interpreter in the seven days preceding completion of the survey. Seventy six of $86(88.4 \%)$ of those departments using face to face interpreters had experienced difficulty obtaining an interpreter out of hours. Nationally, the following proportion of all A\&E departments listed the named language as occurring among the three most common languages requiring interpretation: French 0.46 (95\% confidence interval 0.42 to 0.50 ), Urdu 0.30 (0.26 to 0.34$)$, and German 0.24 (0.21 to 0.27).

Conclusions-There is widespread need and support for a national telephone interpreter service that would match the requirements of 24 hour emergency health care provision.

(F Accid Emerg Med 1999;16:271-274)
\end{abstract}

Keywords: interpreter use; translating; language; communication barriers

Accident and

Emergency

Department, St

Thomas' Hospital,

Lambeth Palace Road,

London SE1 7EH

$P$ Leman

D J Williams

Correspondence to:

Dr Leman, Specialist

Registrar.

Accepted 20 March 1999 resource by patients who are otherwise unable to access health care. ${ }^{1}$ Some of the main difficulties in $A \& E$ are the significant out of

Patients who can communicate poorly, if at all ethnic groups. ${ }^{3}$ Accident and emergency (A\&E) departments are at the forefront of this hours workload and the immediate access required to interpreter services at all times. ${ }^{4}$ While face to face interpreters are often available during normal working hours, there may be difficulties in obtaining this service out of hours. There is little information on how different $A \& E$ departments cope with these difficulties. This questionnaire survey was designed to assess whether one possible solution to this problem, a national telephone interpreter service, was supported by $A \& E$ consultants. The survey was also conducted to assess interpreter need and usage throughout $\mathrm{A} \& \mathrm{E}$ departments in the UK.

\section{Methods}

A named consultant from all $A \& E$ departments seeing more than 25000 new patients per annum and listed in The Directory of Emergency and Special Care Units 1997 was sent a postal questionnaire survey in the last week of January 1998. The questionnaire had previously been piloted in eight A\&E departments in the South Thames region; no significant changes were made. Non-responders were sent a second copy of the questionnaire after four weeks. All replies received by the beginning of April 1998 were analysed.

The questionnaire was divided into three sections and was accompanied by a covering letter detailing the background for the survey. The first section contained three questions: the name of the hospital, the predominant population (inner city, urban, rural, mixed), and the number of new patients seen per annum.

The second section dealt with the variation in languages requiring an interpreter in each $A \& E$ department and was assessed by two methods. Firstly, respondents were asked to tick the box of any language that had required any form of interpreter in their department during the previous seven days. Forty three different languages were given as options and space was provided to record any other languages not listed. This question aimed to provide information as to the overall variation in languages for which interpretation may be required in A\&E departments. Secondly the respondents were asked to record the three languages most commonly requiring interpreters that were ever heard in their departments, not necessarily in the last seven days. This provided information on the most common languages requiring an interpreter in $A \& E$ departments. On the back of the questionnaire in this section were two questions: on how often interpreters had been required in the last seven days (none, 1-4, 5-10, 11-20, >20) and what type of population they came from (local, tourists/overseas visitors, or both). 


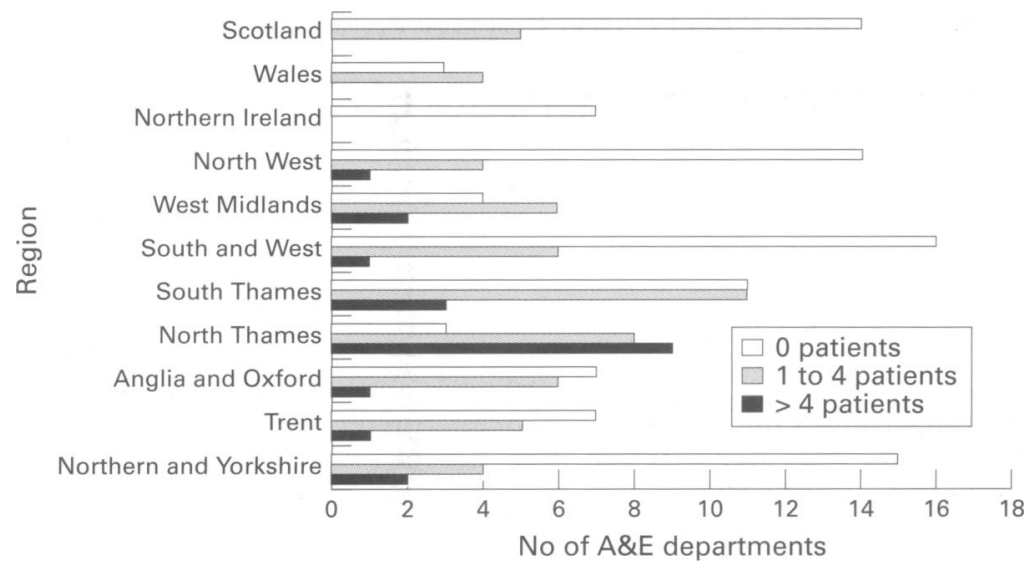

Figure 1 Number of $A \mathcal{E} E$ departments that required an interpreter in the previous seven days in each NHS region categorised by the number of patients that required an interpreter (where recorded, $n=180$ ).

The third section of the questionnaire aimed to detail the type and perceived effectiveness of current interpreting services and to determine support and factors influencing support for a national telephone interpreter service. Respondents were asked to tick boxes of any of the types of interpreter services that were used in their departments (translation cards/books, relatives and friends, staff members (medical), staff members (non-medical), face to face professional interpreters, a telephone interpreter service). Those respondents who used a telephone interpreter service were asked to rank the difficulty (always, often, occasionally, and never) in obtaining a face to face interpreter in three modalities: in a specific language, in a reasonable time (1-2 hours), and at nights and weekends. Users of a telephone service were also asked if their service was provided locally or nationally, and whether or not the department had to pay for the service. All respondents were asked whether or not they would support a national telephone interpreter service available 24 hours a day.

Comparison of categorical data was carried out with the $\chi^{2}$ test without Yates' correction. Where expected cell values were $<5$ in $>20 \%$ of cells, Fisher's exact test was used. A value of $\mathrm{p}<0.05$ was considered to be significant.

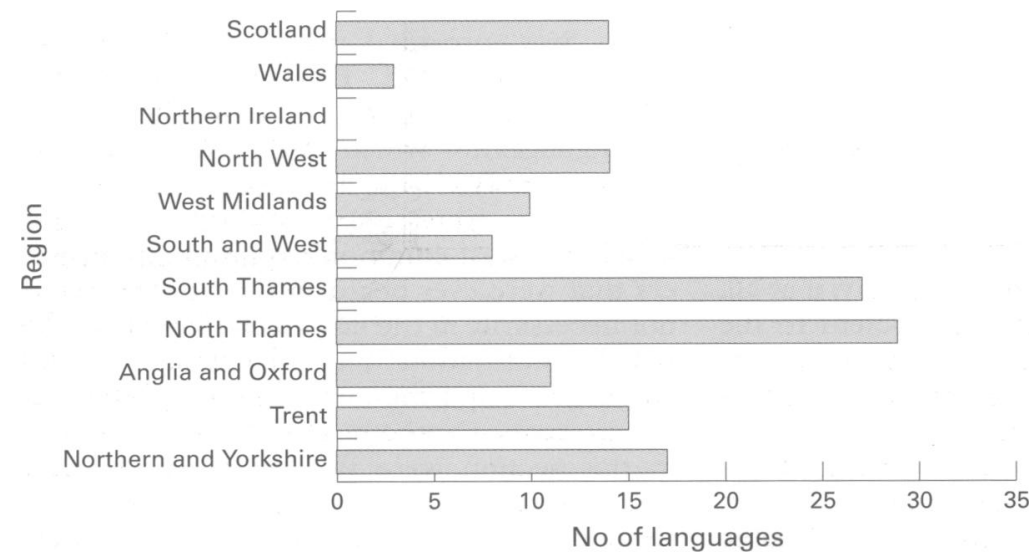

Figure 2 Total number of different languages that required an interpreter in the previous seven days in each NHS region.

\section{Results}

A total of 255 A\&E departments were identified and 197 replies were received, a response rate of $77.3 \%$. The response rate varied between regions from a high of 23/25 $(92.0 \%)$ in South and West to a low of $13 / 22$ $(59.1 \%)$ in West Midlands. This was not a statistically significant difference in response rate $\left(\chi^{2}=12.76, \mathrm{df}=10, \mathrm{p}=0.2376\right)$. Eleven $(5.6 \%)$ respondents did not complete the back of the questionnaire (part of section two and all of section three) and have not been included in those analyses.

Overall 124/186 (66.7\%) departments supported the concept of a national telephone interpreter service. Thirty six of $186(19.4 \%)$ did not support it and 26/186 (14.0\%) replies did not express an opinion. Several local departmental factors were compared between the departments supporting the concept and those either not supporting it or undecided. The comparisons assessed were: inner city compared with rural departments (Fisher's exact test, two sided probability, $p=1$ ), a requirement for an interpreter in the last seven days compared with no requirement $\left(\chi^{2}=0.16\right.$, $\mathrm{df}=1, \mathrm{p}=0.69)$, local population needs compared with tourist needs $\left(\chi^{2}=0.65, \mathrm{df}=1\right.$, $\mathrm{p}=0.42)$, or current use of a telephone interpreter service $\left(\chi^{2}=0.01, \mathrm{df}=1, \mathrm{p}=0.93\right)$. Thus, no significant differences were found in local departmental factors affecting support for a national telephone interpreter service.

There were 180 completed responses to the categorical question on how often interpreters had been required in the last seven days (none, $1-4,5-10,11-20,>20)$. In $79(43.8 \%)$ of the responding departments some form of interpreter had been used in the previous seven days. These departments were no more likely to be described as inner city/urban than rural or mixed catchment areas $\left(\chi^{2}=2.71, \mathrm{df}=1\right.$, $\mathrm{p}=0.10)$. Twenty one $(11.7 \%)$ departments had required some form of interpreter at least five times or more during that period. There was a significant difference between NHS regions with regard to interpreter need in the seven days preceding receipt of the survey $\left(\chi^{2}=\right.$ $32.41, \mathrm{df}=10, \mathrm{p}=0.0003)$. The number of departments requiring an interpreter in the last seven days was highest in North Thames $(17 / 20,85 \%)$ and the West Midlands (8/12, $66.7 \%)$ and lowest in Northern Ireland $(0 / 7$, $0 \%)$, Scotland $(5 / 19,26.3 \%)$, and North West $(5 / 19,26.3 \%)$. This is presented in greater detail graphically in fig 1 .

We used two methods to describe the languages needs in each $A \& E$ department. The tick boxes were used to assess the overall variation in languages requiring interpreters but gave no indication of frequency in individual A\&E departments. Thirty eight different language groups were identified as requiring some form of interpreter during the seven day period (including sign language). In each region a different total number of languages required an interpreter and this is presented in fig 2 . Overall, French was the language most commonly marked (44 separate A\&E departments), followed by Spanish (31), Urdu (26), and 
Table 1 Language needs by NHS region; the figures given are the proportion of $A \mathcal{E} E$ departments in that region which listed that language as occurring among the three commonest languages requiring an interpreter (with $95 \%$ confidence intervals)

\begin{tabular}{|c|c|c|c|c|c|c|}
\hline Region & Language & Proportion & Language & Proportion & Language & Proportion \\
\hline Scotland & French & $0.47(0.34$ to 0.60$)$ & German & $0.42(0.29$ to 0.55$)$ & Chinese & $0.32(0.20$ to 0.44$)$ \\
\hline Wales & Welsh & $0.72(0.57$ to 0.87$)$ & French & $0.55(0.38$ to 0.72$)$ & Spanish & $0.27(0.12$ to 0.42$)$ \\
\hline Northern Ireland & Spanish & $0.62(0.43$ to 0.81$)$ & Chinese & $0.50(0.30$ to 0.70$)$ & French/Polish/ Portuguese & $0.38(0.19$ to 0.57$)$ \\
\hline North West & Urdu & $0.50(0.38$ to 0.62$)$ & Punjabi & $0.29(0.19$ to 0.39$)$ & Chinese/French & $0.25(0.15$ to 0.35$)$ \\
\hline West Midlands & Urdu & $0.54(0.38$ to 0.62$)$ & Hindi & $0.31(0.16$ to 0.46$)$ & Spanish & $0.23(0.10$ to 0.36$)$ \\
\hline South and West & French & $0.87(0.79$ to 0.95$)$ & German & $0.48(0.36$ to 0.60$)$ & Spanish & $0.26(0.16$ to 0.36$)$ \\
\hline South Thames & French & $0.58(0.47$ to 0.69$)$ & Spanish & $0.31(0.21$ to 0.41$)$ & German & $0.27(0.17$ to 0.37$)$ \\
\hline North Thames & French & $0.38(0.26$ to 0.50$)$ & Hindi & $0.24(0.13$ to 0.35$)$ & Somalian/Urdu & $0.24(0.13$ to 0.35$)$ \\
\hline Trent & Hindi & $0.35(0.21$ to 0.49$)$ & French & $0.29(0.15$ to 0.43$)$ & Urdu & $0.29(0.15$ to 0.43$)$ \\
\hline Northern and Yorkshire & Urdu & $0.42(0.31$ to 0.53$)$ & French & $0.33(0.22$ to 0.39$)$ & German & $0.29(0.19$ to 0.39$)$ \\
\hline Nationally & French & $0.46(0.42$ to 0.50$)$ & Urdu & $0.30(0.26$ to 0.34$)$ & German & $0.24(0.21$ to 0.27$)$ \\
\hline
\end{tabular}

Nationally the next most prevalent languages were Spanish 0.22 (0.19 to 0.25$)$, Hindi 0.18 (0.15 to 0.21 ), and Punjabi 0.15 (0.12 to 0.18 ).

German (20). The recording of the three commonest languages requiring any form of interpreter attempted to give a picture of the overall need by language group for interpreters, these findings are summarised in table 1 .

The requirement for interpreters arose mostly from tourists and overseas visitors in $82 / 186(44.1 \%)$ departments and from the local population in $51 / 186(27.4 \%)$ departments. The remainder arose from a combination of these two groups or were not specified.

In each department various resources are used to deal with interpreter needs. One hundred and sixty three of $186(87.6 \%)$ departments used bilingual medical and nursing staff, and 160/186 (86.0\%) patients' relatives and friends. One hundred and eight of $186(58.1 \%)$ used non-medical bilingual staff and $105 / 186(56.5 \%)$ used translation cards or books. With regard to professional interpreter services, 86/186 (46.2\%) departments used face to face interpreters and $33 / 186(17.7 \%)$ used a local telephone interpreter service. Of those departments using face to face interpreters, $77 / 86(89.5 \%)$ had at least some degree of difficulty obtaining an interpreter in the required language, $77 / 86(89.5 \%)$ difficulty in obtaining an interpreter in less than two hours, and $76 / 86(88.4 \%)$ difficulty in obtaining an interpreter out of hours.

\section{Discussion}

We have shown that a significant majority of $A \& E$ consultants support the development of a national telephone interpreter service that can meet the needs of the 24 hour A\&E department. This is not supported merely by those working in the inner cities with large multiethnic populations, but also those where nonEnglish speakers are much less common. It is often the departments with a large predictable need that have developed a local response. However, those departments with a lesser day to day need for interpreters have some of the greatest difficulties in treating non-English speaking patients when they do present. Though many local systems are used, few could cope with the myriad of potential first languages that may be required.

We have also shown that across the UK there is a significant need for interpreter services in A\&E departments for both the local nonEnglish speaking population as well as for tourists and visitors. The questionnaire was sent out in January, a time when there are substantially fewer visitors to the UK than in the summer, and the responses will have underestimated the annual problem. None the less, large numbers of patients were seen during the seven day period for whom some form of interpreter was required. Forty two per cent of departments had required an interpreter on one or more occasions in the previous seven days. There are differences across the UK in the frequency with which languages are heard most commonly, and these most probably reflect local immigrant populations ${ }^{6}$ and variations in overseas tourist travel.

Many departments rely upon patients' family and friends to interpret for them, and while this often has the advantage of easy availability the pitfalls have been well defined. ${ }^{78}$ These include the often poor English language skill of the person chosen to interpret, the difficulties of using a child to interpret complicated or potentially embarrassing information, as well as the victims of domestic violence having the violent partner act as interpreter. It is to prevent problems in this area or to help patients without a family member to interpret that a professional interpreter is required. It is obviously most useful if the attending health care worker is fluently bilingual in the appropriate language as happens in certain parts of the country, for example Wales. In nonemergency medicine practice, family health services authorities and some general practitioner listings often contain information regarding languages spoken in various surgeries to enable patients to consider this when registering with a practice. In an $\mathrm{A} \& \mathrm{E}$ department, however, this is of little value and use must therefore be made of face to face interpreters and telephone interpreters.

We have also shown that there are widespread difficulties in obtaining face to face interpreters within a reasonable time, especially out of hours. Even telephone services, if limited to locally available interpreters, can find it difficult to provide all the languages that may be required. Very few departments in this survey used telephone interpreters but many recognised and supported the concept of a nationally available telephone interpreter service. Indeed, there is growing recognition of the need for a 24 hour telephone interpreter service. ${ }^{2}$ In Australia, a government supported national telephone interpreter service provides 
interpreting in over 100 languages across the country. This is available not only to the health sector but also to social services, the courts, and many other government agencies. ${ }^{9}$ By using telephone links to all parts of the country an appropriate interpreter can usually be found to provide third party interpreting rapidly. Certainly the development of the NHS Direct ${ }^{10}$ network could be seen as a model for a national telephone advice system, which could be expanded to include telephone interpretation. It is acknowledged that there are problems with telephone interpreters such as difficulty in using a mobile handset with the very sick, the telephone acting as a barrier to communication rather than an aid, and also difficulties with deaf patients.

Further research is needed to define the actual costs to the NHS of providing this service, though most NHS trusts currently provide various expensive ad hoc services and the pooling of these resources may well be one cost option. Overall, we believe that a national telephone interpreter service that provides rapid access to a wide range of language interpretation 24 hours a day, seven days a week, is required to cover the work of not only $A \& E$ departments, but also other areas of the NHS where language is a barrier to effective communication.

We wish to thank Sasha Holt for her assistance in organising the mailing of the questionnaires and data entry.

Conflict of interest: none.

Funding: none.

1 Free $\mathrm{C}, \mathrm{McKee} \mathrm{M}$. Meeting the needs of black and minority ethnic groups. BMF 1998;316:380.

2 Jones D, Gill P. Breaking down language barriers. $B M F$ 1998;316:1476.

3 Department of Health. The new NHS: modern, dependable. London: HMSO, 1997.

4 Leman P. Interpreter use in an inner city accident \& emergency department. F Accid Emerg Med 1997;14:98-100.

5 CMA Medical Data. The directory of emergency and special care units 1997. Cambridge: Cambridge Research Laboratories, 1997.

6 Office of Population Censuses and Surveys. 1991 Census. Topic reports for health areas-Great Britain. London: Topic reports for

7 Phelan M, Parkman S. How to do it-work with an Phelan M, Parkman S. How to

8 Baker DW, Parker RM, Williams MV, et al. Use and effectiveness of interpreters in an emergency department. fAMA 1996;275:783-8.

9 Commonwealth of Australia, Department of Immigration and Ethnic Affairs. Translating and interpreting service-a guide to services. Edition No 2. Canberra: Department of Immigration and Ethnic Affairs, July 1994

10 Pencheon D. NHS Direct [editorial]. BMF 1998;317:10267. 